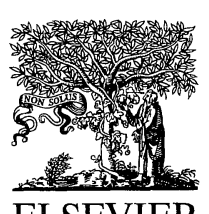

ELSEVIER
International Journal of Risk \& Safety in Medicine 6 (1995) 191-192

\title{
Profile
}

\section{INRUD: the International Network for Rational Use of Drugs}

The International Network for Rational Use of Drugs (INRUD) was set up in 1989 with the goal of promoting the rational use of pharmaceuticals; its emphasis is heavily on the developing world.

Prominent features of INRUD's strategy to achieve its goal include:

- an interdisciplinary focus, linking clinical and social sciences

- activities originating from country-based core groups of individuals representing ministries of health, universities, non-governmental organizations and private sector institutions

- belief in the importance of sharing relevant experiences and in technical cooperation among participating individuals

- emphasis on understanding behavioral aspects of drug use, particularly beliefs and motivation of providers and consumers

- promotion of well-designed research studies to understand these behavioral factors, leading to reproducible interventions to improve drug use

- development of useful tools for research, including standard research methodologies, simplified sampling and data collection strategies, and useraccessible computer software

- cooperation among donors to fund activities that contribute to these objectives.

There is a network committee with members in eight developing countries, and expert support groups exist within W.H.O., at Harvard Medical School (USA), the Karolinska Institute (Sweden), the University of Newcastle (Australia) and Management Sciences for Health (Boston, MA, USA). One prominent activity of INRUD itself is a series of courses on Promoting Rational Drug Use, but the network also links closely with other bodies in organizing meetings and seminars; it is closely involved in the MSH Rational Pharmaceutical Management project supported by the US Agency for International Development (USAid). INRUD NEWS appears quarterly and is obtainable from the Network Coordinator in Boston, MA. 
Further information: Dr. Richard Laing, Network Coordinator for INRUD, Management Sciences for Health, 165 Allandale Road, Boston, MA 02130-3400, USA.

Tel. (+1-617) 524-7799; Fax (+1-617) 524-2825; E-Mail: INRUD@warren. med.harvard.edu 